Ralf Grüttemeier · Hybride Welten 


\section{Ralf Grüttemeier}

\section{Hybride Welten}

Aspekte der „Nieuwe Zakelijkheid“ in der niederländischen Literatur 
Die Deutsche Bibliothek - CIP-Einheitsaufnahme

\section{Griittemeier, Ralf:}

Hybride Welten : Aspekte der "nieuwe zakelijkheid“ in der niederländischen Literatur / Ralf Grüttemeier. - Stuttgart :

$\mathrm{M}$ und $\mathrm{P}_{1}$ Verl. für Wiss. und Forschung, 1995

Zugi.: Amsterdam, Univ., Diss., 1994

ISBN 978-3-476-45130-9

ISBN 978-3-476-45130-9

ISBN 978-3-476-04226-2 (eBook)

DOI 10.1007/978-3-476-04226-2

Dieses Werk ist einschließlich aller seiner Teile geschützt. Jede Verwertung außerhalb der engen Grenzen des Urheberrechtsgesetzes ist ohne Zustimmung des Verlages unzulässig und strafbar. Das gilt insbesondere für Vervielfältigungen, Übersetzungen, Mikroverfilmungen und Einspeichenung in elektronischen Systemen.

M \& P Verlag für Wissenschaft und Forschung ein Verlag der J.B. Metzlerschen Verlagsbuchhandlung und Carl Emst Poeschel Verlag GmbH in Stuttgart

(C) 1995 Springer-Verlag GmbH Deutschland

Ursprünglich erschienen bei J.B. Metzlersche Verlagsbuchhandlung und Carl Ernst Poeschel Verlag GmbII in Stuttgart 1995 


\section{INHALT}

1. Die Nieuwe Zakelijkheid in der niederländischen Literaturwissenschaft 12

1.1 Kontingenz und Homogenität

1.2 Die Dominanz von Forum

1.3 Die Dominanz der idealistischen Ästhetik

2. Die Neue Sachlichkeit in der Germanistik 37

2.1 Primat des Stoffs und Objektivität 38

2.2 Idealistische Ästhetik 41

2.3 Intentionalität 45

3. Facetten einer externen Poetik der Nieuwe Zakelijkheid 53

3.1 Constant van Wessem: organische Faktizität 54

3.2 M. Revis: 'Dieses wundersame Gleichgewicht zwischen Verwerfen und gleichzeitigem Akzeptieren' $\quad 60$

3.3 Jef Last: eine dokumentarische Poetik 68

4. Metaphern in $8.100 .000 \mathrm{~m}^{3}$ zand und Gelakte hersens 74

4.1 Metaphern als Fortsetzung der Tendenz mit anderen Mitteln? 76

4.2 Die hybride Rhetorik von M. Revis $\quad 80$

4.3 Tendenz oder Hybride? 92

5. Rhetorische Reflexivität 96

$\begin{array}{lr}5.1 \text { Metapher } & 96\end{array}$

$\begin{array}{lr}5.2 \text { Metonymie } & 100\end{array}$

5.3 Metapher versus Metonymie 107

$\begin{array}{ll}5.4 \text { Verortung } & 108\end{array}$

$\begin{array}{ll}5.5 \text { Verfahren des Auslassens } & 114\end{array}$

6. Typographie im Dienste von Dialogizität 122

6.1 Stromans Stad: typographische Mimesis? 127

6.2 Wageners Sjanghai: Prinzip Skepsis 138 
7. Redevielfalt in Jef Lasts Partij remise und Zuiderzee 147

$\begin{array}{ll}7.1 \text { Dokumente } & 148\end{array}$

$\begin{array}{lc}7.2 \text { Sprache } & 158\end{array}$

$\begin{array}{ll}7.3 \text { Intention } & 170\end{array}$

8. Redevielfalt bei M. Revis und F. Bordewijk 183

$\begin{array}{lll}8.1 & 8.100 .000 \mathrm{~m}^{3} \text { zand: Statistik und Vanitas } & 184\end{array}$

8.2 Bint: Pädagogik und Initiation 198

9. Versuch einer Historisierung der Nieuwe Zakelijkheid 220

9.1 Modernisierung in den Niederlanden in der Zwischenkriegszeit 225

$\begin{array}{ll}9.2 \text { Hybridität } & 229\end{array}$

9.3 Die moderne Massengesellschaft 233

9.4 Formale Strenge, Exaktheit und Metaphysik 236

10. Die dreißiger Jahre zwischen Erstarrung und Tauwetter 246

$\begin{array}{ll}10.1 \text { Erstarrung } & 246\end{array}$

10.2 Auftauen $\quad 252$

$\begin{array}{ll}\text { Ausblick } & 261\end{array}$

$\begin{array}{lr}\text { Romane } & 266\end{array}$

$\begin{array}{ll}\text { Bibliographie } & 267\end{array}$ 